\title{
Biological Variation of Creatinine, Cystatin C, and eGFR over 24 Hours
}

Citation for published version (APA):

Hilderink, J. M., van der Linden, N., Kimenai, D. M., Litjens, E. J. R., Klinkenberg, L. J. J., Aref, B. M., Aziz, F., Kooman, J. P., Rennenberg, R. J. M. W., Bekers, O., Koopmans, R. P., \& Meex, S. J. R. (2018). Biological Variation of Creatinine, Cystatin C, and eGFR over 24 Hours. Clinical Chemistry, 64(5), 851860. https://doi.org/10.1373/clinchem.2017.282517

Document status and date:

Published: 01/05/2018

DOI:

10.1373/clinchem.2017.282517

Document Version:

Publisher's PDF, also known as Version of record

Document license:

Taverne

Please check the document version of this publication:

- A submitted manuscript is the version of the article upon submission and before peer-review. There can be important differences between the submitted version and the official published version of record.

People interested in the research are advised to contact the author for the final version of the publication, or visit the DOI to the publisher's website.

- The final author version and the galley proof are versions of the publication after peer review.

- The final published version features the final layout of the paper including the volume, issue and page numbers.

Link to publication

\footnotetext{
General rights rights.

- You may freely distribute the URL identifying the publication in the public portal. please follow below link for the End User Agreement:

www.umlib.nl/taverne-license

Take down policy

If you believe that this document breaches copyright please contact us at:

repository@maastrichtuniversity.nl

providing details and we will investigate your claim.
}

Copyright and moral rights for the publications made accessible in the public portal are retained by the authors and/or other copyright owners and it is a condition of accessing publications that users recognise and abide by the legal requirements associated with these

- Users may download and print one copy of any publication from the public portal for the purpose of private study or research.

- You may not further distribute the material or use it for any profit-making activity or commercial gain

If the publication is distributed under the terms of Article $25 \mathrm{fa}$ of the Dutch Copyright Act, indicated by the "Taverne" license above, 


\title{
Biological Variation of Creatinine, Cystatin $C$, and eGFR over 24 Hours
}

\author{
Judith M. Hilderink, ${ }^{1}$ Noreen van der Linden, ${ }^{1}$ Dorien M. Kimenai, ${ }^{1}$ Elisabeth J.R. Litjens, ${ }^{2}$ \\ Lieke J.J. Klinkenberg, ${ }^{1 \dagger}$ Breshna M. Aref, ${ }^{1}$ Fahra Aziz, ${ }^{1}$ Jeroen P. Kooman, ${ }^{2}$ Roger J.M.W. Rennenberg, ${ }^{3}$ \\ Otto Bekers, ${ }^{1}$ Richard P. Koopmans, ${ }^{3}$ and Steven J.R. Meex ${ }^{1 *}$
}

BACKGROUND: Estimated glomerular filtration rate (eGFR) is widely used in clinical practice. This study assessed the within-subject biological variation $\left(\mathrm{CV}_{\mathrm{I}}\right)$ of different eGFR equations in people with chronic kidney disease (CKD) and people without CKD. The aims of this study were $(a)$ to determine the 24-h biological variation profiles of creatinine, cystatin $C$, and eGFR and $(b)$ to determine whether $\mathrm{CV}_{\mathrm{I}}$ of creatinine, cystatin $\mathrm{C}$, and eGFR changes on deterioration of glomerular filtration.

METHODS: Hourly blood samples were analyzed from 37 individuals (17 without CKD, 20 with CKD) during 24 h. Creatinine (enzymatic method) and cystatin $C$ were measured using a Cobas 8000 (Roche Diagnostics). eGFR was estimated using the Modification of Diet in Renal Disease and the Chronic Kidney Disease Epidemiology Collaboration based on creatinine and/or cystatin C. Plasma samples were stored at $-80{ }^{\circ} \mathrm{C}$ before analysis. Outlier and homogeneity analyses were checked before performing a nested ANOVA to determine biological variation.

RESULTS: $\mathrm{CV}_{\mathrm{I}}$ of creatinine was higher in people without CKD than in those with CKD (6.4\% vs $2.5 \%)$ owing primarily to the more profound effect of meat consumption on creatinine variability in individuals with lower baseline creatinine concentrations. Unlike creatinine, cystatin $\mathrm{C}$ concentrations were unaffected by meat consumption. Cystatin $\mathrm{C}$ showed some diurnal rhythmic variation and less in people with CKD. Reference change values (RCVs) of all eGFR equations were within $13 \%$ to $20 \%$ in both study groups.
Conclusions: Despite differences in $\mathrm{CV}_{\mathrm{I}}$ of creatinine, the $\mathrm{CV}_{\mathrm{I}}$ and $\mathrm{RCV}$ of the eGFR equations were relatively similar for people with or without CKD.

(C) 2018 American Association for Clinical Chemistry

The estimated glomerular filtration rate $(e G F R)^{4}$ is widely applied for the diagnosis of kidney disease and the monitoring of renal function in patients with chronic kidney disease (CKD) (1). CKD is defined as the presence of kidney damage or a glomerular filtration rate $(\mathrm{GFR})<60 \mathrm{~mL} / \mathrm{min} / 1.73 \mathrm{~m}^{2}$ for $\geq 3$ months, irrespective of the cause $(1,2)$. The Chronic Kidney DiseaseEpidemiology Collaboration equation (CKD-EPI) and the Modification of Diet in Renal Disease (MDRD) are the equations most commonly used in clinical practice to estimate the $\operatorname{GFR}(3,4)$. Although the equations are constructed differently, the calculation of both CKD-EPI and MDRD is based on the 2 renal biomarkers: creatinine and cystatin $C(3-5)$. Serum creatinine and cystatin $\mathrm{C}$ concentrations can fluctuate during the day, either from true circadian differences in GFR or from random biological variation, without reflecting real changes $(6,7)$. These fluctuations could affect the interpretation of eGFR values based on creatinine and/or cystatin C. Insight regarding the magnitude of diurnal fluctuations may prevent physicians from erroneously interpreting random variations as clinically relevant changes (8).

Biological variation studies allow a systematic assessment of random diurnal variation of biomarkers. Thus far, most studies that have assessed the biological variation of renal biomarkers and eGFR reported on betweenday variation $(6,9-17)$, but data on within-day biolog-

\footnotetext{
${ }^{1}$ Department of Clinical Chemistry, Central Diagnostic Laboratory, Maastricht University Medical Center, Maastricht, the Netherlands; ${ }^{2}$ Department of Nephrology, Maastricht University Medical Center, Maastricht, the Netherlands; ${ }^{3}$ Department of Internal Medicine, Maastricht University Medical Center, Maastricht, the Netherlands.

* Address correspondence to this author at: Central Diagnostic Laboratory, Department of Clinical Chemistry, Cardiovascular Research Institute Maastricht (CARIM), Maastricht University Medical Center (MUMC), P.0. Box 5800, 6202 AZ Maastricht, the Netherlands. Fax +31-(0)43-3874692; e-mail steven.meex@mumc.nl.

${ }^{\dagger}$ Current affiliation: Clinical Laboratory, Department of Clinical Chemistry, Catharina Hospital, Eindhoven, the Netherlands.
}

Received October 9, 2017; accepted February 7, 2018.

Previously published online at DOI: 10.1373/clinchem.2017.282517

C 2018 American Association for Clinical Chemistry

${ }^{4}$ Nonstandard abbreviations: eGFR, estimated glomerular filtration rate; $C K D$, chronic kidney disease; GFR, glomerular filtration rate; CKD-EPI, Chronic Kidney DiseaseEpidemiology Collaboration; MDRD, Modification of Diet in Renal Disease; $\mathrm{CV}_{A^{\prime}}$ analytical coefficient of variation; $\mathrm{CV}_{1}$, intraindividual coefficient of variation; $\mathrm{CV}_{\mathrm{G}}$ group coefficient of variation; RCV, reference change value; II, index of individuality. 
ical variation are scarce (18). Moreover, most studies focused on either healthy volunteers or people with impaired renal function, but data from a direct comparison of people with and without $\mathrm{CKD}$ are not available $(6,15,19,20)$. In this study, we aimed to construct 24-h profiles of creatinine and cystatin $\mathrm{C}$ concentrations, as well as GFR estimations that are based on creatinine and/or cystatin C. In addition, we assessed whether variation over the day is of similar magnitude in people with $\mathrm{CKD}$ and people without CKD.

\section{Materials and Methods}

\section{STUDY DESIGN AND POPULATION}

This study on 24-h variability in renal function and eGFR was performed between January 2013 and October 2015 , as described previously $(21,22)$. It conformed to the principles of the Declaration of Helsinki (23) and was approved by the Institutional Review Board and the ethics committee at Maastricht University Medical Center. Each participant provided written informed consent.

The design of this study complied with the current checklists regarding biological variation as much as possible $(24,25)$.

In total, 44 individuals were included and divided into 2 study groups: The first study group consisted of 24 individuals without clinically diagnosed CKD (79\% males and 21\% females), and the second group (70\% males and 30\% females) consisted of 20 patients (participant numbers 25-44) with clinically diagnosed CKD stage 3 or higher (eGFR, $<60 \mathrm{~mL} / \mathrm{min} / 1.73 \mathrm{~m}^{2}$ ) (2). This number of individuals per group afforded sufficient power to make reliable estimations about biological variation (26). All individuals were white and between 39 and 83 years of age. Diabetes was defined as fasting plasma glucose $\geq 126 \mathrm{mg} / \mathrm{dL}$ and/or $\mathrm{HbAlc} \geq 6.5 \%$ $(=47 \mathrm{mmol} / \mathrm{mol})(27)$. Exclusion criteria were current dialysis treatment, an acute myocardial infarction in the 12 months before the study, active cardiac disease (angina pectoris, cardiomyopathy, or myocarditis), and anemia (hemoglobin, $<10.5 \mathrm{~g} / \mathrm{dL}$ ).

\section{SAMPLE COLLECTION AND HANDLING}

Creatinine and cystatin $\mathrm{C}$ were measured on a Cobas ${ }^{\circledR}$ 8000 (Roche Diagnostics) using the following Roche reagents: CREP2 (Creatinine plus ver.2, code 05168589) and CYSC2 (Tina-quant Cystatin C Gen.2, code 06600239). We used an enzymatic method to measure creatinine, based on the conversion of creatinine with the aid of creatininase, creatinase, and sarcosine oxidase to glycine, formaldehyde, and hydrogen peroxide. We used Bio-Rad controls for creatinine and Cystatin C Control Set Gen. 2 for cystatin C (Roche Diagnostics).

The eGFR was calculated using MDRD and CKDEPI formulae $(3,5)$. Three CKD-EPI estimations were calculated: CKD-EPI ${ }_{\text {creatinine, }}$ CKD-EPI $I_{\text {cystatin } C}$, and CKD-EPI creatinine-cystatin C $_{\text {(4). }}$.

Hourly blood samples were drawn in EDTAcontaining tubes $(8 \mathrm{~mL})$. The plasma samples were centrifuged immediately (centrifugation at $2700 \mathrm{~g}$ for $12 \mathrm{~min}$ at room temperature) after collection, and plasma was stored at $-80{ }^{\circ} \mathrm{C}$ until analysis. The plasma samples were then thawed, and all samples from the same individual were analyzed within a single run.

To estimate analytical variation $\left(\mathrm{CV}_{\mathrm{A}}\right)$, samples from 8 randomly selected individuals (4 individuals without CKD and 4 individuals with CKD, 18\% of all samples) were analyzed in duplicate.

\section{STUDY PROCEDURE}

To study the within-day biological variability, blood samples were drawn every hour during $24 \mathrm{~h}$ using an intravenous cannula. The participants arrived at $8 \mathrm{AM}$ at the laboratory after an overnight fast. During the test day, participants were restricted to the laboratory under sedentary conditions. Mealtimes were standardized at 8:30 AM (breakfast), 12:30 PM (lunch), and 6 PM (dinner). The participants could select from approximately 4 dinner options. The majority of dinner options consisted of dishes containing meat. The meal options and meat content were not standardized. Breakfast and lunch consisted of sandwiches with cheese, ham, or sweet toppings. The participants went to bed at 11:30 PM and got up the next morning at 7 AM. During the night, an extension line was attached to the cannula to prevent sleep disturbance during blood sampling.

\section{STATISTICAL ANALYSIS}

As recommended for biological variation studies, we performed outlier analyses on 3 levels (analytical, withinsubject, and between-subject) $(7,26)$. The Cochran test was used to identify outliers on the analytical and withinsubject level, and the Dixon-Reed criterion was performed to identify outliers on the between-subject level $(7,8,28,29)$. People with outlying within-subject variances were rejected from calculations because of their heterogeneity of variance (24). Because data on the analytical, within-subject, and between-subject levels followed a gaussian distribution (Shapiro-Wilk test), transformation of the data was not required. For the analytical normality check, we used data of 8 individuals that were measured in duplicate (192 replicates). For the withinsubject level, we verified normality for each participant. For the between-subject level, we verified normality for the means of each individual. The variation on 3 levels, the between-subject variation $\left(\mathrm{CV}_{\mathrm{G}}\right)$, within-subject biological variation $\left(\mathrm{CV}_{\mathrm{I}}\right)$, and $\mathrm{CV}_{\mathrm{A}}$, were calculated using a nested ANOVA with $95 \%$ CIs determined according to the method of Burdick and Graybill $(8,26,30)$. 
Table 1. Baseline characteristics. ${ }^{a}$

\begin{tabular}{|c|c|c|}
\hline & $\begin{array}{l}\text { People without } \\
\text { CKD }(n=17)\end{array}$ & $\begin{array}{l}\text { People with } \\
\text { CKD }(n=20)\end{array}$ \\
\hline Age, years & $72 \pm 7$ & $66 \pm 12$ \\
\hline Male sex & $14(82)$ & $14(70)$ \\
\hline Body mass index, $\mathrm{kg} / \mathrm{m}^{2}$ & $26 \pm 3$ & $28 \pm 4$ \\
\hline Diabetes mellitus $^{b}$ & $6(35)$ & $7(35)$ \\
\hline Cholesterol concentration, mg/dL & $176 \pm 35$ & $157 \pm 33$ \\
\hline Systolic blood pressure, $\mathrm{mmHg}$ & $140 \pm 15$ & $136 \pm 19$ \\
\hline Diastolic blood pressure, $\mathrm{mmHg}$ & $68 \pm 8$ & $86 \pm 14$ \\
\hline Creatinine, mg/dL & $1.0 \pm 0.2$ & $3.3 \pm 1.0$ \\
\hline Cystatin C, mg/L & $1.0 \pm 0.2$ & $2.8 \pm 0.8$ \\
\hline MDRD, $\mathrm{mL} / \mathrm{min} / 1.73 \mathrm{~m}^{2}$ & $73.4 \pm 18.5$ & $19.2 \pm 6.4$ \\
\hline CKD-EPI $\left.\right|_{\text {creatinine, }} \mathrm{mL} / \mathrm{min} / 1.73 \mathrm{~m}^{2}$ & $72.9 \pm 17.2$ & $18.9 \pm 6.6$ \\
\hline CKD-EPI ${ }_{\text {cystatin }} \mathrm{C} \mathrm{mL} / \mathrm{min} / 1.73 \mathrm{~m}^{2}$ & $74.2 \pm 17.2$ & $20.2 \pm 8.5$ \\
\hline 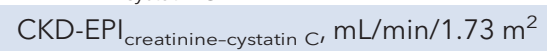 & $74.2 \pm 17.2$ & $19.0 \pm 7.0$ \\
\hline CKD & $0(0)$ & $20(100)$ \\
\hline Glomerular disease & $N A^{c}$ & $7(35)$ \\
\hline Tubulointerstitial disease & NA & $4(20)$ \\
\hline Vascular disease & NA & $8(40)$ \\
\hline Cystic and congenital disease & NA & $1(5)$ \\
\hline
\end{tabular}

Reference change values (RCVs) (Z-score of 1.96) and the index of individuality (II) were calculated according to the method of Fraser and Harris (8):

$$
\begin{aligned}
\mathrm{RCV} & =\sqrt{2} \times Z \times \sqrt{\left(\mathrm{CV}_{\mathrm{I}}^{2}+\mathrm{CV}_{\AA}^{2}\right)} \\
\| & =\sqrt{\left(\mathrm{CV}_{\mathrm{I}}^{2}+\mathrm{CV}_{\AA}^{2}\right)} / \mathrm{CV}_{\mathrm{G}}
\end{aligned}
$$

We used an $F$-test to monitor whether the degree of renal impairment was stable in the people with CKD. To investigate this, we examined the eGFR 1 week, 1 month, and 3 months after the initial test day. $P$ values $<0.05$ were considered statistically significant.

To visualize the diurnal rhythm of cystatin C, 24-h concentration curves were fitted for both study groups using cosinor rhythmometry.

All statistical calculations were performed using SPSS for Windows version 23 (IBM SPSS Statistics).

\section{Results}

\section{ELIGIBILITY OF PARTICIPANTS}

A total of 44 individuals, 24 without CKD and 20 with $\mathrm{CKD}$, participated in this biological variation study. Two participants (1 and 8) left the study prematurely, and 2 other participants (15 and 23) had missing data because of problems with the venous cannula overnight. To maintain a balanced design, and in line with the statistical conditions for a nested ANOVA, these people were considered not eligible and excluded from further analyses (31). Additionally, participant 20 was excluded because this participant developed a severe cold during the test day; therefore, the clinical situation of this participant was unstable. Although participants 10 and 18 were not clinically diagnosed with $\mathrm{CKD}$, these participants were excluded because the creatinine concentrations were not appropriate for the non-CKD group (mean concentrations, $1.8 \pm 0.2 \mathrm{mg} / \mathrm{dL}$ and $2.0 \pm 0.08 \mathrm{mg} / \mathrm{dL}$, respectively). In Fig. 1 of the Data Supplement that accompanies the online version of this article at http://www. clinchem.org/content/vol64/issue5, a flowchart of the study is shown. Eventually, 37 individuals were considered eligible for analyses. Baseline characteristics of the 2 study groups are shown in Table 1.

\section{CLINICAL STABILITY OF PEOPLE WITH CKD}

To verify that the people with CKD were clinically stable and not rapidly progressive in terms of their $\mathrm{CKD}$, additional blood samples were taken at 1 week, 1 month, and 3 months after the test day at the same time as the baseline measurement on the initial test day (8:30 AM). The eGFR 
values (calculated with MDRD, CKD-EPI ${ }_{\text {creatinine }}$ CKD$\mathrm{EPI}_{\text {cystatin C}}$, and CKD-EPI $\mathrm{I}_{\text {creatinine-cystatin C) }}$ did not decrease significantly during this follow-up period (minimum-maximum follow-up concentration ranges: MDRD, $18.7-19.3 \mathrm{~mL} / \mathrm{min} / 1.73 \mathrm{~m}^{2}, P=0.63$; CKD $\mathrm{EPI}_{\text {creatinine }}, 18.3-18.9 \mathrm{~mL} / \mathrm{min} / 1.73 \mathrm{~m}^{2}, P=0.99$; CKD-EPI ${ }_{\text {cystatin C }}, 20.1-20.3 \mathrm{~mL} / \mathrm{min} / 1.73 \mathrm{~m}^{2}, P=$

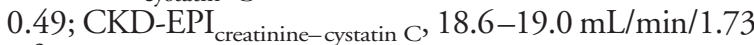
$\left.\mathrm{m}^{2}, P=0.99\right)$. Therefore, the participants with CKD were considered as having a stable chronic disease.

\section{4-H VARIABILITY PROFILES}

Figs. 1 and 2 show 24-h variability profiles of creatinine, cystatin C, and all eGFR equations for both study groups. The mean creatinine and cystatin $\mathrm{C}$ concentrations were, by definition, significantly lower in people without CKD than in those with CKD (creatinine: $1.0 \pm$ $0.3 \mathrm{mg} / \mathrm{dL}$ vs $3.3 \pm 1.0 \mathrm{mg} / \mathrm{dL}, P<0.01$; cystatin $\mathrm{C}$ : $1.0 \pm 0.3 \mathrm{mg} / \mathrm{L}$ vs $2.7 \pm 0.8 \mathrm{mg} / \mathrm{L}, P<0.01)$. Consequently, all average eGFR values were significantly higher in people without CKD compared with the people with CKD (MDRD: $75 \pm 21 \mathrm{~mL} / \mathrm{min} / 1.73 \mathrm{~m}^{2}$ vs $20 \pm 9 \mathrm{~mL} / \mathrm{min} / 1.73 \mathrm{~m}^{2}, P<0.01$; CKD$\mathrm{EPI}_{\text {creatinine: }}: 74 \pm 18 \mathrm{~mL} / \mathrm{min} / 1.73 \mathrm{~m}^{2}$ vs $20 \pm 10$ $\mathrm{mL} / \mathrm{min} / 1.73 \mathrm{~m}^{2}, P<0.01 ;$ CKD-EPI ${ }_{\text {cystatin } \mathrm{C}}: 77 \pm$ $17 \mathrm{~mL} / \mathrm{min} / 1.73 \mathrm{~m}^{2}$ vs $24 \pm 14 \mathrm{~mL} / \mathrm{min} / 1.73 \mathrm{~m}^{2}$,

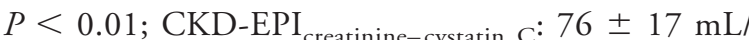
$\mathrm{min} / 1.73 \mathrm{~m}^{2}$ vs $21 \pm 12 \mathrm{~mL} / \mathrm{min} / 1.73 \mathrm{~m}^{2}, P<0.01$ ).

Creatinine concentrations increased up to $50 \%$ $(0.46 \mathrm{mg} / \mathrm{dL})$ in people without CKD after dinner (participant 11 , individual 24 -h profile of this participant was not shown). The increase was numerically similar in people with CKD $(0.40 \mathrm{mg} / \mathrm{dL})$ compared with people without $\mathrm{CKD}$, but as a percentage, the increase was substantially lower $(18 \%)$ because of the high baseline concentrations of creatinine in the people with CKD.

Unlike creatinine, cystatin $\mathrm{C}$ concentrations were not affected by dinner. Interestingly, however, cystatin C showed a small, but evident, diurnal rhythm, with decreasing cystatin $\mathrm{C}$ concentrations during daytime and increasing concentrations during the evening and night. This circadian rhythm of cystatin $\mathrm{C}$ was less prominent in people with CKD (Figs. 1 and 2). In Fig. 2 of the online Data Supplement, the diurnal rhythm of cystatin $\mathrm{C}$ was visualized by fitting a cosinor model through the average data points. For people without CKD, the amplitude of the diurnal cosinor rhythm was $4.9 \pm 0.8 \%$, whereas the amplitude was reduced to $1.6 \pm 0.5 \%$ for people with CKD.

\section{COMPONENTS OF VARIATION IN PEOPLE WITH AND WITHOUT CKD}

Variation components of all parameters in both study groups are shown in Table $2 . \mathrm{CV}_{\mathrm{G}}$ was of similar magnitude for the study groups. In both groups, $\mathrm{CV}_{\mathrm{G}}$ was significantly larger than $\mathrm{CV}_{\mathrm{I}}$ for all parameters. Because of the relatively high $\mathrm{CV}_{\mathrm{G}}$ values, all indexes of individuality were low $(0.1-0.3)$.

In Fig. 3, the minimum-maximum concentration ranges of creatinine and cystatin $\mathrm{C}$ are presented for the people without and with $\mathrm{CKD}$. The people without CKD (Fig. 3A) exhibit a higher relative range in creatinine concentrations than the people with CKD (Fig. $3 \mathrm{C})$. This difference in concentrations contributes to a significantly higher $\mathrm{CV}_{\mathrm{I}}$ expressed as percent in people without $\mathrm{CKD}$ (6.4\% vs $2.5 \%$ ); also, the RCV was significantly higher in people without CKD (18\% vs $8 \%)$. The $\mathrm{CV}_{\mathrm{I}}$ values of cystatin C, CKD-EPI $\mathrm{cystatin}_{\mathrm{C}}$, and CKD-

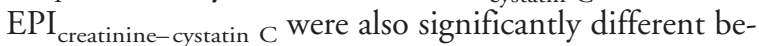
tween the groups. However, these differences were smaller than for creatinine.

In people without $\mathrm{CKD}$, the CKD-EPI based on the combination of creatinine and cystatin C (CKD$\mathrm{EPI}_{\text {creatinine-cystatin C}}$ ) was the eGFR equation with lowest $\mathrm{CV}_{\mathrm{I}}$. In people with $\mathrm{CKD}$, the CKD-EPI based on creatinine (CKD-EPI creatinine $_{\text {) demonstrated the lowest }} \mathrm{CV}_{\mathrm{I}}$ over the day. However, in this group, the difference with

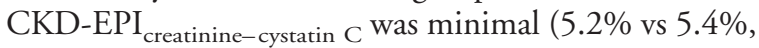
with overlapping CIs).

$\mathrm{CV}_{\mathrm{A}}$ was low in both study groups (maximum $2.0 \%$ for people without $\mathrm{CKD}$ and $2.6 \%$ for people with $\mathrm{CKD})$. All $\mathrm{CV}_{\mathrm{A}}$ values met the desirable ratio between $\mathrm{CV}_{\mathrm{I}}$ and $\mathrm{CV}_{\mathrm{A}}$, which is 1:2. A ratio $<0.5$ ensures that the analytical noise contributes $<12 \%$ to the total variation (7).

\section{SENSITIVITY ANALYSIS}

According to the Cochran within-subject outlier test, the after-dinner increase of creatinine demanded the exclusion of some individuals (participants 14 and 30, respectively; see Table 1 and Fig. 3 in the online Data Supplement). However, this strict statistical perspective may neglect the fact that the creatinine increases are in fact physiological changes that also occur in hospitalized patients. We believe that excluding these participants may be too stringent and can lead to an underestimation of biological variation data. A sensitivity analysis included individuals who were excluded in the primary analysis because of heterogeneity of variance. In this analysis, slightly larger $\mathrm{CV}_{\mathrm{I}}$ values were revealed for most biomarkers (see Table 2 in the online Data Supplement). The difference was more pronounced for creatinine than for cystatin C (which lacks the after-dinner increase), and the effect was stronger in people without CKD than in people with CKD.

\section{Discussion}

In the current study, we present 24-h variation profiles of creatinine, cystatin $\mathrm{C}$, and their derived estimates of GFR 

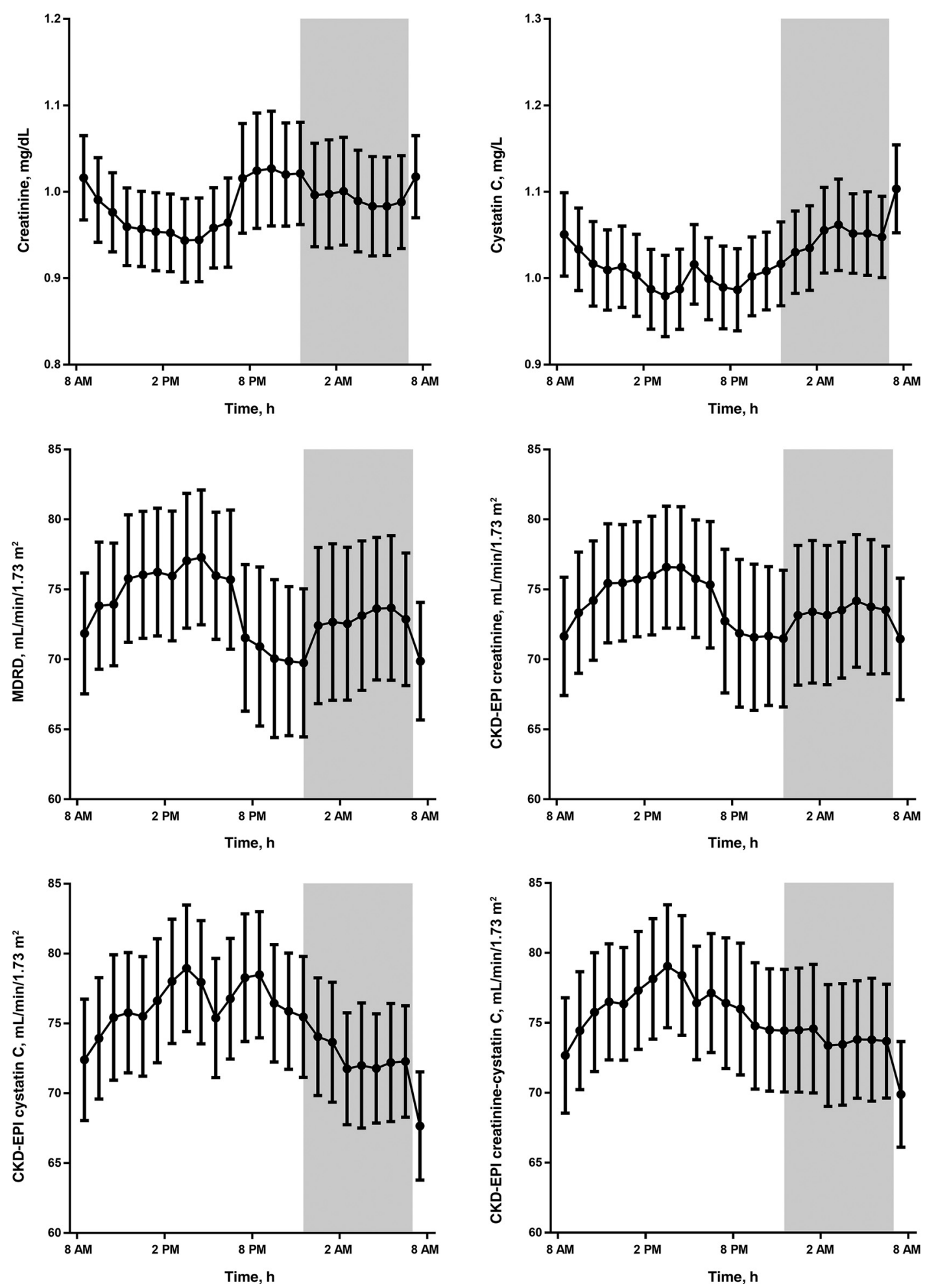

Fig. 1. Twenty-four-hour variation profiles in people without CKD.

Values represent mean (SE). Participants slept between 11:30 PM and 7 AM (shaded area). 


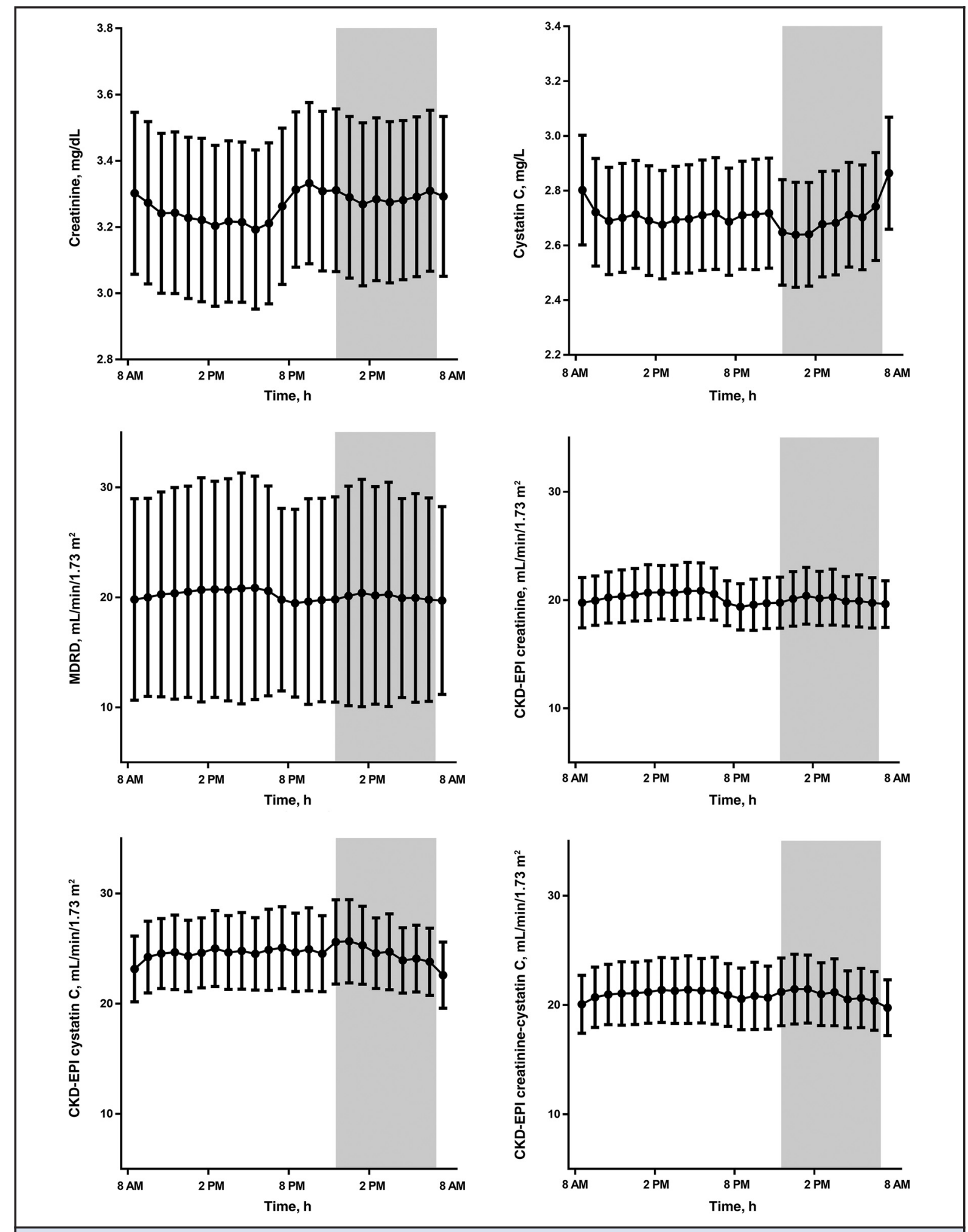

Fig. 2. Twenty-four-hour variation profiles in people with CKD.

Values represent mean (SE). Participants slept between 11:30 PM and 7 AM (shaded area). 
Table 2. Components of biological variation, Ils, and RCVs for renal biomarkers and different eGFR equations in both study groups. ${ }^{a}$

\begin{tabular}{|c|c|c|c|c|c|c|c|}
\hline & $\mathrm{n}$ & Mean & $\mathrm{CV}_{\mathrm{A}}$ & $\mathrm{CV}_{1}$ & $\mathrm{CV}_{\mathrm{G}}$ & II & $\mathrm{RCV}$ \\
\hline \multicolumn{8}{|l|}{ People without CKD } \\
\hline Creatinine & 16 & $1.0 \mathrm{mg} / \mathrm{dL}$ & $1.1(1.0-1.3)$ & $6.4(6.0-6.9)$ & $21.2(15.7-32.9)$ & 0.3 & 18.2 \\
\hline Cystatin C & 17 & $1.0 \mathrm{mg} / \mathrm{dL}$ & $1.1(1.0-1.3)$ & $4.1(3.8-4.4)$ & $15.3(11.3-23.2)$ & 0.3 & 11.6 \\
\hline MDRD & 16 & $75.3 \mathrm{~mL} / \mathrm{min} / 1.73 \mathrm{~m}^{2}$ & $1.6(1.4-1.9)$ & $6.1(5.7-6.6)$ & $27.3(20.2-42.3)$ & 0.2 & 16.9 \\
\hline CKD-EPI creatinine & 16 & $73.8 \mathrm{~mL} / \mathrm{min} / 1.73 \mathrm{~m}^{2}$ & $1.2(1.0-1.4)$ & $5.3(5.1-5.6)$ & $24.3(18.0-37.7)$ & 0.2 & 14.6 \\
\hline CKD-EPI cystatin C $_{\text {C }}$ & 17 & $76.7 \mathrm{~mL} / \mathrm{min} / 1.73 \mathrm{~m}^{2}$ & $2.0(1.8-2.3)$ & $5.5(5.2-5.9)$ & $21.2(15.8-32.3)$ & 0.3 & 15.3 \\
\hline CKD-EPI $\left.\right|_{\text {creatinine-cystatin C }}$ & 16 & $75.2 \mathrm{~mL} / \mathrm{min} / 1.73 \mathrm{~m}^{2}$ & $1.2(1.1-1.4)$ & $4.6(4.3-5.0)$ & $20.3(16.5-34.5)$ & 0.2 & 13.2 \\
\hline \multicolumn{8}{|l|}{ People with CKD } \\
\hline Creatinine & 19 & $3.3 \mathrm{mg} / \mathrm{dL}$ & $1.3(1.1-1.5)$ & $2.5(2.4-2.7)$ & $28.1(21.2-41.6)$ & 0.1 & 7.9 \\
\hline Cystatin C & 18 & $2.7 \mathrm{mg} / \mathrm{L}$ & $0.8(0.7-1.0)$ & $3.2(3.0-3.4)$ & $27.2(20.4-40.8)$ & 0.1 & 9.1 \\
\hline MDRD & 19 & $20.2 \mathrm{~mL} / \mathrm{min} / 1.73 \mathrm{~m}^{2}$ & $2.4(2.1-2.8)$ & $5.5(5.2-5.9)$ & $28.4(21.5-42.0)$ & 0.2 & 13.3 \\
\hline CKD-EPI creatinine $_{\text {e }}$ & 19 & $20.1 \mathrm{~mL} / \mathrm{min} / 1.73 \mathrm{~m}^{2}$ & $2.6(2.3-3.0)$ & $5.2(4.9-5.6)$ & $30.0(22.7-44.4)$ & 0.2 & 14.4 \\
\hline CKD-EPI $I_{\text {cystatin C }}$ & 18 & $23.8 \mathrm{~mL} / \mathrm{min} / 1.73 \mathrm{~m}^{2}$ & $1.2(1.1-1.4)$ & $7.3(6.8-7.8)$ & $38.7(29.1-58.1)$ & 0.2 & 20.1 \\
\hline CKD-EPI creatinine-cystatin C & 17 & $20.9 \mathrm{~mL} / \mathrm{min} / 1.73 \mathrm{~m}^{2}$ & $1.6(1.4-1.8)$ & $5.4(5.0-5.8)$ & $35.2(26.4-52.9)$ & 0.2 & 15.1 \\
\hline
\end{tabular}

(MDRD, CKD-EPI ${ }_{\text {creatinine, CKD-EPI }}$ cystatin C, and

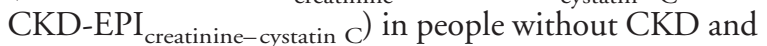
in people with CKD. In addition, separate variation components were calculated and compared between both study groups.

An important finding of this study is that the $\mathrm{CV}_{\mathrm{I}}$ of creatinine is significantly higher in people without CKD than in people with CKD. In our study, the effect of the postdinner creatinine spike on $\mathrm{CV}_{\text {I }}$ was substantial, especially for people without $\mathrm{CKD}$, given that these people have low baseline creatinine concentrations (mean, 1.0 $\mathrm{mg} / \mathrm{dL}$ ). For people with $\mathrm{CKD}$, the effect on $\mathrm{CV}_{\mathrm{I}}$ because of higher baseline creatinine concentrations (mean, 3.3 $\mathrm{mg} / \mathrm{dL}$ ) was smaller. This difference was even slightly more pronounced in the sensitivity analysis that included the individuals with a (physiological) high postdinner creatinine increase, likely because of meat consumption, increasing their $\mathrm{CV}_{\mathrm{I}}$ and marking them for removal based on statistical criteria. However, the variation in creatinine concentrations caused by dinner content is of interest for clinical practice, given that patients often have dinner with unknown meat and other content. For clinical practice, this variation might ideally be included, even if this variation is statistically large and seemingly divergent. Rivara et al. performed a similar sensitivity analysis in which they showed a slight increase of the $\mathrm{CV}_{\mathrm{I}}$ of creatinine after including individuals who were excluded in the primary analysis because of heterogeneity of variances (19).

The $\mathrm{CV}_{\mathrm{I}}$ for creatinine in this study was higher than reported in the EUBIVAS project (6.2\% vs $4.4 \%$ ), which can likely be attributed to the fact that the creatinine concentrations measured in the EUBIVAS project were between-day $\mathrm{CV}_{\mathrm{I}}$ values based on fasting blood samples collected once per day at the same hour between 8 AM and $10 \mathrm{AM}(20,32)$. Therefore, creatinine increase after meat consumption is not integrated in the EUBIVAS $\mathrm{CV}_{\mathrm{I}}$ value. Because within-day $\mathrm{CV}_{\mathrm{I}}$ and between-day $\mathrm{CV}_{\mathrm{I}}$ are different concepts, the results of this study are not directly comparable with those of the EUBIVAS project.

The design of this study complies with the current checklists regarding biological variation as much as possible $(24,25)$. Only on item 7 of the most recent biological variation checklist, which is about the steady-state condition, do we deviate from the checklist by not including meat consumption in the model for the concentration of creatinine to create a steady state. Whether meat consumption is included in a model for the concentration of creatinine has consequences for the amount of variation left unexplained, and with that, the size of the $\mathrm{CV}_{\mathrm{I}}$. In a clinical setting, neither the time of dinner of a patient nor the meat content of the dinner (or other meal) is known to the physician interpreting the creatinine laboratory results. Hence, for clinical purposes, variation resulting from meat consumption should not be excluded from the model and should be included in the $\mathrm{CV}_{\mathrm{I}}$ estimate to allow for this additional uncertainty. Because most people consume meat in their diet, our $\mathrm{CV}_{\mathrm{I}}$ estimate for a 24-h period can be considered to reflect typical physiologic conditions facing interpretation of creatinine and eGFR results. 


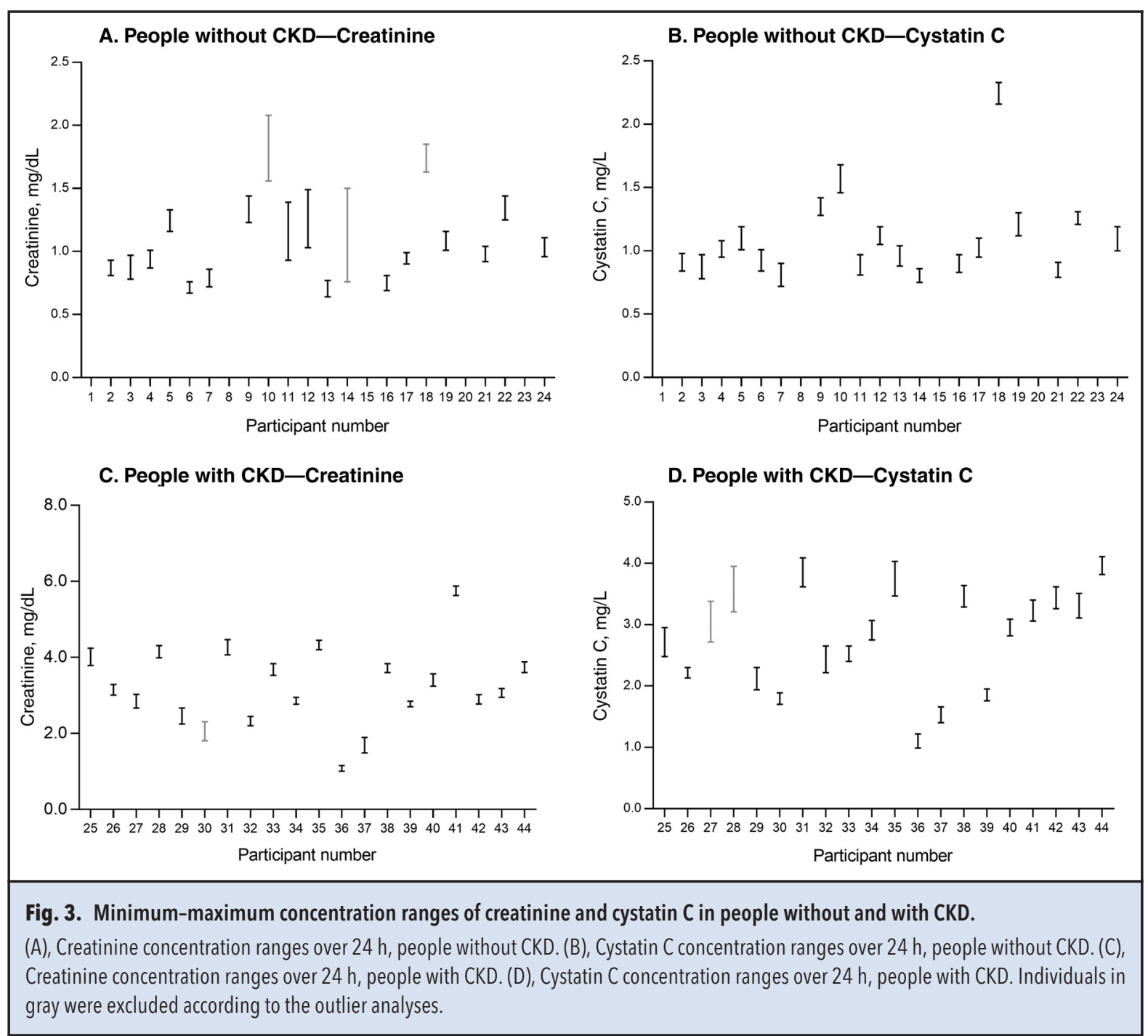

Because this study was not originally designed to investigate the influence of meat consumption on creatinine concentrations, no detailed individual data of the participants regarding their meat consumption during the day were available. However, the study of Nair et al. standardized the meat consumption of all participants and compared their results with a nonmeat meal. The Nair study described a significant increase of creatinine concentration after a meat meal for all study participants (33). For healthy volunteers and individuals with CKD stage 1 or 2 , the study reported statistically significant creatinine increases of $5 \mu \mathrm{mol} / \mathrm{L}(0.06 \mathrm{mg} / \mathrm{dL})$ and 8 $\mu \mathrm{mol} / \mathrm{L}(0.09 \mathrm{mg} / \mathrm{dL})$, respectively. We observed a similar average increase of $0.07 \mathrm{mg} / \mathrm{dL}(6.2 \mu \mathrm{mol} / \mathrm{L})$ between $6 \mathrm{PM}$ and $10 \mathrm{PM}$, presumably related to dinner composition. For people with CKD, the Nair study reported maximum creatinine increases of up to 0.25 $\mathrm{mg} / \mathrm{dL}(22 \mu \mathrm{mol} / \mathrm{L})$, which is more pronounced than the

average increase of $0.13 \mathrm{mg} / \mathrm{dL}(12 \mu \mathrm{mol} / \mathrm{L})$ we observed in the people with CKD.

Nevertheless, the study of Nair et al. emphasizes the finding that the relative decrease in eGFR after meat consumption is proportionately less in patients with more advanced CKD stages (33), which is consistent with our findings. Another study by Preiss et al. demonstrated that the effect of meat consumption could have an impact on diagnosis because of misclassification of CKD staging if measurements are made after consuming a cooked-meat meal (34). The authors of this study state that physicians should ensure that, when classifying the stage of CKD, samples are taken under appropriate conditions (34). We endorse this conclusion, especially in the context of a 24-h biological variation study. Creatinine was included in our study to be able to determine the calculated eGFR and not to be an indicator for GFR (35). 
Unlike creatinine, the $\mathrm{CV}_{\mathrm{I}}$ of cystatin $\mathrm{C}$ was in the same range for both people with or without $\mathrm{CKD}$, and its 24-h profile was not characterized by a postdinner spike. Despite substantial differences in biological variation and RCVs between cystatin $\mathrm{C}$ and creatinine, especially in people without $\mathrm{CKD}$, these differences do not translate to similar differences in the biological variation and RCVs of the eGFR equations that are derived from these biomarkers. In fact, $\mathrm{CV}_{\mathrm{I}}$ values and $\mathrm{RCV}$ s of the $\mathrm{CKD}$ EPI $I_{\text {creatinine }}$ equation are of the same magnitude in both study groups. However, $\mathrm{CV}_{\mathrm{I}}$ values and $\mathrm{RCV}$ s of the CKD-EPI cystatin $C_{C}$ are of different magnitude. The transformation from cystatin $\mathrm{C}$ to $\mathrm{CKD}-\mathrm{EPI}_{\text {cystatin }}$ leads to more dispersed CKD-EPI values than the transformation from creatinine to $\mathrm{CKD}-\mathrm{EPI} \mathrm{I}_{\text {creatinine }}$.

Diurnal cystatin C profiles showed modest intrinsic diurnal rhythmicity, with a slight decrease during daytime and an increase during the evening and night. This is in line with modestly reduced glomerular filtration at nighttime compared with daytime $(36,37)$. A similar diurnal rhythmicity may be apparent in the creatinine profiles (at least a declining pattern from morning until evening) but is obscured by the postdinner creatinine peak. Interestingly, the diurnal cystatin $C$ rhythm is somewhat diminished in people with CKD. This effect can be explained by reduced renal clearance in people with $\mathrm{CKD}$, leading to accumulation of cystatin $\mathrm{C}$, and consequent reduction in its diurnal rhythm (38).

Large rhythmic diurnal oscillations preclude calculation of overall variation components and RCVs, as they would become dependent on time of day. Instead, hourto-hour RCVs can be calculated, which consider the structural change according to the diurnal rhythm. Such approach has been previously applied by our group and others for the calculation of RCVs for various hematological biomarkers and cardiac troponin $\mathrm{T}(39,40)$. However, rhythmic variation of cystatin $\mathrm{C}$ in this study was so small that the calculation of hour-to-hour variation components and RCVs would have complicated their interpretation without offering substantial benefit in terms of mathematical accuracy.

Some limitations of this study merit consideration: First, the design of the study was not limited to the assessment of the biological variation of kidney biomarkers. Although mealtimes were standardized across study par- ticipants, the content of the meals was not. Hence, the consumption of meat among meals was variable and may have accounted for the highly variable creatinine increases, especially after dinner.

Second, the ratio between men and women was skewed ( $77 \%$ men and $23 \%$ women), precluding robust assessment of potential sex differences. Third, the generalizability of this study to other ethnicities may be limited because all participants were white. Fourth, most individuals, including those without CKD, had comorbidities. Nevertheless, the presence of comorbidities, as well as the fact that the meals were not standardized, is representative for the average patient (both hospitalized and outpatient) and provides real world estimates of the biological variation of interest when interpreting results.

In conclusion, we show that the $\mathrm{CV}_{\mathrm{I}}$ of creatinine is higher in people without CKD than in people with CKD. Despite differences in biological variation, RCVs of all derived estimates of GFR (MDRD, CKD-EPI ${ }_{\text {creatinine }}$, CKD$\mathrm{EPI}_{\text {cystatin C}}$, and CKD-EPI $\mathrm{I}_{\text {creatinine-cystatin C }}$ ) are within the same range $(13 \%-20 \%)$ and are similar for people with or without $\mathrm{CKD}$.

\begin{abstract}
Author Contributions: All authors confirmed they have contributed to the intellectual content of this paper and have met the following 3 requirements: (a) significant contributions to the conception and design, acquisition of data, or analysis and interpretation of data; (b) drafting or revising the article for intellectual content; and (c) final approval of the published article.
\end{abstract}

Authors' Disclosures or Potential Conflicts of Interest: Upon manuscript submission, all authors completed the author disclosure form. Disclosures and/or potential conflicts of interest.

Employment or Leadership: None declared.

Consultant or Advisory Role: None declared.

Stock Ownership: None declared.

Honoraria: None declared.

Research Funding: S.J.R. Meex, Roche Diagnostics, an Academic Incentive Grant from Maastricht University Medical Center.

Expert Testimony: None declared.

Patents: None declared.

Role of Sponsor: The funding organizations played no role in the design of study, choice of enrolled patients, review and interpretation of data, or final approval of manuscript.

Acknowledgments: The authors thank V.W. Kleijnen for his skillful laboratory assistance.

\section{References}

1. Stevens $P E$, Levin A. Kidney disease: improving global outcomes chronic kidney disease guideline development work group M. Evaluation and management of chronic kidney disease: synopsis of the kidney disease: improving global outcomes 2012 clinical practice guideline. Ann Intern Med 2013;158:825-30.

2. Levey AS, Stevens LA, Coresh J. Conceptual model of CKD: applications and implications. Am J Kidney Dis 2009;53:54-16.
3. Levey AS, Bosch JP, Lewis JB, Greene T, Rogers N, Roth D. A more accurate method to estimate glomerular filtration rate from serum creatinine: a new prediction equation. Modification of Diet in Renal Disease Study Group. Ann Intern Med 1999;130:461-70.

4. Inker $L A$, Schmid $C H$, Tighiouart $H$, Eckfeldt JH, Feldman $\mathrm{HI}$, Greene T, et al. Estimating glomerular filtration rate from serum creatinine and cystatin C. N Engl J Med 2012:367:20-9.
5. Levey AS, Stevens LA, Schmid CH, Zhang YL, Castro AF 3rd, Feldman $\mathrm{HI}$, et al. A new equation to estimate glomerular filtration rate. Ann Intern Med 2009;150:604 12.

6. Carter JL, Parker CT, Stevens PE, Eaglestone G, KnightS, Farmer CK, Lamb EJ. Biological variation of plasma and urinary markers of acute kidney injury in patients with chronic kidney disease. Clin Chem 2016;62:876-83.

7. Fraser CG. Biological variation: from principles to prac- 
tice. Washington (DC): AACC Press; 2001.

8. Fraser CG, Harris EK. Generation and application of data on biological variation in clinical chemistry. Crit Rev Clin Lab Sci 1989;27:409-37.

9. Ozturk OG, Paydas S, Balal M, Sahin G, Karacor ED, Ariyurek SY, Yaman A. Biological variations of some analytes in renal posttransplant patients: a different way to assess routine parameters. J Clin Lab Anal 2013;27: 438-43.

10. Delanaye P, Cavalier E, Depas G, Chapelle JP, Krzesinski JM. New data on the intraindividual variation of cystatin C. Nephron Clin Pract 2008;108:c246-8.

11. Larsson $A$, Akerstedt $T$, Hansson $L O$, Axelsson J. Circadian variability of cystatin $C$, creatinine, and glomerular filtration rate (GFR) in healthy men during normal sleep and after an acute shift of sleep. Chronobiol Int 2008; 25:1047-61.

12. Carobene A, Graziani MS, Lo Cascio C, Tretti L, Cremo nese $E$, Yabarek $T$, et al. Age dependence of within subject biological variation of nine common clinical chemistry analytes. Clin Chem Lab Med 2012;50: 841-4.

13. Reinhard M, Erlandsen EJ, Randers E. Biological variation of cystatin C and creatinine. Scand J Clin Lab Invest 2009;69:831-6.

14. Fraser CG, Williams $P$. Short-term biological variation of plasma analytes in renal disease. Clin Chem 1983;29: $508-10$

15. Selvin $E$, Juraschek $S P$, Eckfeldt J, Levey $A S$, Inker $L A$, Coresh J. Within-person variability in kidney measures. Am J Kidney Dis 2013;61:716-22.

16. Pascoe PJ, Gallagher CS, Fraser CG. Components of biological variation of some serum analytes in hospitalized pregnant women. Clin Chem 1984;30:583-4

17. Gowans EM, Fraser CG. Biological variation of serum and urine creatinine and creatinine clearance: ramifications for interpretation of results and patient care. Ann Clin Biochem 1988;25(Pt 3):259-63.

18. Ravn $B$, Larsson A, Martensson J, Martling CR, Bell M

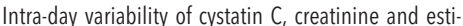
mated GFR in intensive care patients. Clin Chim Acta 2016:460:1-4.

19. Rivara $M B$, Zelnick $L R$, Hoofnagle $A N$, Newitt $R$, Tracy $\mathrm{RP}, \mathrm{Kratz} \mathrm{M}$, et al. Diurnal and long-term variation in plasma concentrations and renal clearances of circulating markers of kidney proximal tubular secretion. Clin Chem 2017;63:915-23.

20. Carobene A, Marino I, Coskun A, Serteser M, Unsal I, Guerra $E$, et al. The EuBIVAS project: within-and between-subject biological variation data for serum creatinine using enzymatic and alkaline picrate methods and implications for monitoring. Clin Chem 2017; 63:1527-36

21. Klinkenberg LJ, Wildi $K$, van der Linden $N$, Kouw IW, Niens $M$, Twerenbold R, et al. Diurnal rhythm of cardiac troponin: consequences for the diagnosis of acute myocardial infarction. Clin Chem 2016;62:1602-11.

22. van der Linden $N$, Hilderink JM, Cornelis $T$, Kimenai DM, Klinkenberg LJJ, van Doorn WP, et al. Twenty-fourhour biological variation profiles of cardiac troponin I in individuals with or without chronic kidney disease. Clin Chem 2017;63:1655-6

23. World Medical Association. Declaration of Helsinki: ethical principles for medical research involving human subjects. JAMA 2013;310:2191-4.

24. Bartlett WA, Braga F, Carobene $A$, Coskun A, Prusa R, Fernandez-Calle $\mathrm{P}$, et al. A checklist for critical appraisal of studies of biological variation. Clin Chem Lab Med 2015;53:879-85.

25. Aarsand AK, R Raas T, Fernandez-Calle P, Ricos C, DiazGarzon J, Jonker N, et al. The biological variation data critical appraisal checklist: a standard for evaluating studies on biological variation. Clin Chem 2018;64: 501-14

26. Roraas $T$, Petersen PH, Sandberg S. Confidence intervals and power calculations for within-person biological variation: effect of analytical imprecision, number of replicates, number of samples, and number of individuals. Clin Chem 2012;58:1306-13.

27. de Leur K, Vroemen JP, Vos DI, Elmans L, van der Laan L. Outcome after osteosynthesis of hip fractures in nonagenarians. Clin Interv Aging 2014;9:41-9

28. Reed AH, Henry RJ, Mason WB. Influence of statistical method used on the resulting estimate of normal range. Clin Chem 1971;17:275-84

29. Dixon WJ. Processing data for outliers. Biometrics 1953:9:74-89.

30. Burdick RK, Graybill FA. Confidence intervals on vari- ance components. New York (NY): Marcel Dekker; 1992

31. McDonald JH. Handbook of biological statistics. 3rd Ed. Baltimore (MD): Sparky House Publishing; 2014

32. Carobene A, Strollo M, Jonker N, Barla G, Bartlett WA, Sandberg $S$, et al. Sample collections from healthy volunteers for biological variation estimates' update: a new project undertaken by the working group on biological variation established by the European Federation of Clinical Chemistry and Laboratory Medicine. Clin Chem Lab Med 2016;54:1599-608.

33. Nair S, O'Brien SV, Hayden K, Pandya B, Lisboa PJ, Hardy KJ, Wilding JP. Effect of a cooked meat meal on serum creatinine and estimated glomerular filtration rate in diabetes-related kidney disease. Diabetes Care 2014;37:483-7.

34. Preiss DJ, Godber IM, Lamb EJ, Dalton RN, Gunn IR. The influence of a cooked-meat meal on estimated glomerular filtration rate. Ann Clin Biochem 2007:44:35- 42.

35. Diskin CJ. Creatinine and glomerular filtration rate: evolution of an accommodation. Ann Clin Biochem 2007;44:16-9.

36. Wuerzner $G$, Firsov D, Bonny 0 . Circadian glomerular function: from physiology to molecular and therapeutical aspects. Nephrol Dial Transplant 2014;29:1475-

37. Koopman MG, Koomen GC, Krediet RT, de Moor EA, Hoek FJ, Arisz L. Circadian rhythm of glomerular filtration rate in normal individuals. Clin Sci (Lond) 1989; 77:105-11.

38. van der Linden $N$, Cornelis T, Kimenai DM, Klinkenberg LJJ, Hilderink JM, Luck S, et al. Origin of cardiac troponin T elevations in chronic kidney disease. Circulation 2017:136:1073-5.

39. Hilderink JM, Klinkenberg LJJ, Aakre KM, de Wit NCJ, Henskens YMC, van der Linden N, et al. Within-day biological variation and hour-to-hour reference change values for hematological parameters. Clin Chem Lab Med 2017; 55:1013-24.

40. Aakre KM, Roraas T, Petersen PH, Svarstad E, Sellevoll $\mathrm{H}$, Skadberg 0 , et al. Weekly and 90-minute biological variations in cardiac troponin T and cardiac troponin I in hemodialysis patients and healthy controls. Clin Chem $2014 ; 60: 838-47$ 